\title{
High carriage rate of high-level penicillin-resistant Streptococcus pneumoniae in a Taiwan kindergarten associated with a case of pneumococcal meningitis
}

\author{
Tsai-Ling Lauderdale ${ }^{1}$, Wei Yang Lee ${ }^{2}$, Ming Fang Cheng, 3 , I Fei Huang 3,4, \\ Yu Chen Lin ${ }^{3,4}$, Kai Sheng Hseih ${ }^{3,4}$, I-Wen Huang ${ }^{1}$ and Christine C Chiou*3,4
}

Address: ${ }^{1}$ Division of Clinical Research, National Health Research Institutes, Zhunan, Taiwan, ${ }^{2}$ Kaohsiung Municipal United Hospital, Kaohsiung, Taiwan, ${ }^{3}$ Department of Pediatrics, Veterans General Hospital-Kaohsiung, Kaohsiung, Taiwan and ${ }^{4}$ National Yang-Ming University, Taipei, Taiwan

Email: Tsai-Ling Lauderdale - lauderdale@nhri.org.tw; Wei Yang Lee - weiyanglee@yahoo.com.tw; Ming Fang Cheng - mulstin@sparqnet.net; I Fei Huang - huang.ifei@msa.hinet.net; Yu Chen Lin - yuchlin@yahoo.com.tw; Kai Sheng Hseih - kshseih@isca.vghks.gov.tw; IWen Huang - yvone@nhri.org.tw; Christine C Chiou* - chenchia@yahoo.com

* Corresponding author

Published: 0 I November 2005

BMC Infectious Diseases 2005, 5:96 doi:10.1 I86/147/-2334-5-96
Received: 04 August 2005

Accepted: 01 November 2005

This article is available from: http://www.biomedcentral.com/I47I-2334/5/96

(c) 2005 Lauderdale et al; licensee BioMed Central Ltd.

This is an Open Access article distributed under the terms of the Creative Commons Attribution License (http://creativecommons.org/licenses/by/2.0), which permits unrestricted use, distribution, and reproduction in any medium, provided the original work is properly cited.

\begin{abstract}
Background: The Taiwan ${ }^{19 F}-14$ Streptococcus pneumoniae clone and its variants are being found with increasing frequency in the Asia-Pacific region. A 5-year old child with $\mathrm{S}$. pneumoniae meningitis caused by a high-level penicillin resistant strain $(\mathrm{MIC}=4 \mu \mathrm{g} / \mathrm{ml})$ was admitted to a hospital in southern Taiwan. We carried out a study to determine the potential source of this strain.

Methods: Nasopharyngeal cultures were obtained from all children attending the same kindergarten as the index case. To determine their relatedness all isolates were compared by serotype, antimicrobial susceptibility profile and pulsed field gel electrophoresis (PFGE).

Results: A high proportion of the children including the index case $(32 / 78,41.0 \%)$ carried $S$. pneumoniae in their nasopharynx (NP). The most common serotype was I9F (I3/32, 40.6\%). The PFGE types of the I9F serotype isolates obtained from the patient's blood, CSF and NP were identical and were related to II other serotype I9F NP isolates including 10 that were indistinguishable from the Taiwan ${ }^{19 F_{-}} 14$ clone. All 14 isolates had similar high-level penicillin and multi-drug resistance. The serotypes of the other $19 \mathrm{NP}$ isolates included 6A (2), 6B (10), 23F (5), $9 \mathrm{~V}(\mathrm{I})$ and $3(\mathrm{I})$. The overall rate of penicillin resistance in these $S$. pneumoniae from these children was $87.5 \%$ (28/32), with an $\mathrm{MIC}_{50}$ of 2 and $\mathrm{MIC}_{90}$ of $4 \mathrm{ug} / \mathrm{ml}$. In addition, multi-drug resistant-isolates (isolates resistant to 3 different classes of antimicrobials) accounted for $87.5 \%$ (28/32) of all isolates.

Conclusion: The high carriage rate of high-level penicillin- and multi-drug- resistant $S$. pneumoniae in a kindergarten associated with a case of pneumococcal meningitis emphasizes the need for restraint in antibiotic use and consideration of childhood immunization with conjugate pneumococcal vaccine to prevent the further spread of resistant $S$. pneumoniae in Taiwan.
\end{abstract}

\section{Background}

There has been an alarming increase in recent years in the prevalence of penicillin- resistant $S$. pneumoniae and pneumococcal meningitis caused by penicillin non-susceptible 
S. pneumoniae. Thus far pneumococcal meningitis caused by high-level penicillin resistant strains $(\mathrm{MIC}=4 \mathrm{ug} / \mathrm{ml}$ ) accounts for only a small portion of the cases reported from various countries around the world [1-6]. A case of pneumococcal meningitis caused by a high-level penicillin resistant $S$. pneumoniae $19 \mathrm{~F}$ recently occurred in a 5 year old boy in southern Taiwan. The same microorganism was isolated from his CSF, blood and nasopharynx. We decided to determine whether the source of his infection might be kindergarten children with whom he had close contact. This was based on the knowledge that spread of multi-drug-resistant clones of $S$. pneumoniae occurs in the day-care center and kindergarten settings [710]. The most common clones include Spanish 23F, Taiwan $23 \mathrm{~F}$ and $19 \mathrm{~F}$.

Nasopharyngeal surveillance cultures were performed on all the children who attended the same kindergarten as the patient. All the isolates of $S$. pneumoniae were characterized by susceptibility to a variety of antimicrobial drugs, serotype and pulsed field gel electrophoresis (PFGE) profiles.

\section{Case report}

A 5-year-old boy with a two-day history of fever, vomiting and poor intake was brought to the emergency room of Veterans General Hospital-Kaohsiung, Taiwan in April 2002. He had cough for 2 days before the onset of fever and had visited a pediatric clinic, where oral antibiotics were prescribed. No otitis media or sinusitis was noted upon admission. He also had no prior hospitalizations or any major systemic illness in the past. On admission, his vital signs consisted of a temperature of $38.6^{\circ} \mathrm{C}$ (ear), pulse rate $108 / \mathrm{min}$, respiratory rate $60 / \mathrm{min}$ and blood pressure of 134/87 mmHg. The physical examination revealed a drowsy child with nuchal rigidity and a positive Kernig sign. The Glascow Coma Scale was E1V1 M6. Chest radiography was normal. A lumbar puncture revealed an opening pressure of $>400 \mathrm{mmHg}$. The total white blood cell count of the CSF was $66 / \mathrm{mm}^{3}$, with $28 \%$ neutrophils, $68 \%$ lymphocytes, and $4 \%$ monocytes. The glucose and protein were $11 \mathrm{mg} / \mathrm{dL}$ and $596 \mathrm{mg} / \mathrm{dL}$, respectively. Numerous gram-positive cocci in pairs were seen on microscopic examination. CSF and blood and nasopharyngeal cultures were positive for $\mathrm{S}$. pneumoniae. The $\mathrm{C}$ reactive protein was $12.3 \mathrm{mg} / \mathrm{dL}$ (normal $<1 \mathrm{mg} / \mathrm{dL}$ ). The immunoglobulin profile was within normal limits. The patient was intubated. Cefotaxime $200 \mathrm{mg} / \mathrm{Kg} / \mathrm{D}$ and vancomycin $60 \mathrm{mg} / \mathrm{Kg} / \mathrm{D}$ were administered immediately after lumbar puncture was performed. Dexamethasone $0.6 \mathrm{mg} / \mathrm{Kg} / \mathrm{D}$ was also administered prior to the parenteral antibiotics and continued for 4 days. The isolates obtained from blood, nasopharynx and CSF demonstrated an MIC to penicillin of $4 \mu \mathrm{g} / \mathrm{mL}$. A follow-up lumbar puncture was performed 72 hours after admission.
The CSF glucose was $52 \mathrm{mg} / \mathrm{dL}$ and protein was $292 \mathrm{mg} /$ $\mathrm{dL}$ with a lowered opening pressure. Vancomycin and cefotaxime were administered for a total of 15 days. He became afebrile on the 7th day. He was gradually weaned from the ventilator and fully recovered without neurological sequelae.

\section{Methods \\ Nasopharyngeal cultures}

Surveillance cultures of nasopharynx were performed on all the children who attended the same kindergarten as the patient. Nasopharyngeal culture was also performed on both of the parents and the younger sibling of the index case. Specimens were collected by a single investigator using a cotton swab placed $1-1.5 \mathrm{~cm}$ into the nasopharynx. The specimens were immediately inoculated on a $5 \%$ sheep blood plate (Becton Dickinson Microbiology System, Cockeysville, MD). All plates were incubated for $24-48$ hours at $37^{\circ} \mathrm{C}$ in $5 \%$ carbon dioxide. $\mathrm{S}$. pneumoniae was identified by typical colonial appearance, $\alpha$-hemolysis, and gram stain. Confirmatory tests included optochin sensitivity and bile solubility tests (Becton Dickinson). All isolates were frozen at $-70^{\circ} \mathrm{C}$ in tryptic soy broth for further analysis.

\section{Antimicrobial susceptibility testing}

Minimum inhibitory concentrations were determined using the broth micro-dilution method following the guidelines of Clinical and Laboratory Standards Institute (formerly NCCLS) (CLSI/NCCLS) [11]. A final inoculum of $5 \times 10^{5} \mathrm{CFU} / \mathrm{ml}$ in Mueller-Hinton broth containing 2$5 \%$ lysed horse blood was used to inoculate the Sensititre STPF3 standard plate (Trek Diagnostics, East Essex, England). This device contained the following concentrations of antimicrobials $(\mu \mathrm{g} / \mathrm{ml})$ : amoxicillin/clavulanic acid (216), cefepime (0.12-2), ceftriaxone (0.03-2), cefotaxime (0.12-4), cefuroxime (0.5-4), chloramphenicol (2-16), erythromycin (0.25-2), gatifloxacin (0.5-8), Gemifloxacin (0.03-0.5), levofloxacin (0.5-16), linezolide (0.25-4), meropenem (0.25-2), penicillin (0.03-8), moxifloxacin (0.25-8), tetracycline (0.5-8), trimethoprim/sulfamethoxazole (SXT) (0.5-4), and vancomycin (0.5-4). Interpretive criteria were based on those indicated in CLSI/NCCLS document M100-S14 [12]. In calculating resistance percentages, the 3 isolates from the patient were counted as one.

\section{Serotyping}

Serogrouping and serotyping of S. pneumoniae were performed by the Quelling reaction using Omni serum, followed by pool, group, then factor serum (Statens Serum Institut, Copenhagen, Denmark). 
Table I: Distribution of serotypes, PFGE patterns and antimicrobial susceptibility profiles of 34 isolates of $S$. pnuemoniae isolates from 32 children attending a kindergarten in Kaohsiung, Taiwan

\begin{tabular}{|c|c|c|c|c|c|c|c|c|c|c|c|c|c|c|}
\hline \multirow[t]{2}{*}{ Isolate ${ }^{a}$} & \multirow[t]{2}{*}{ Serotype } & \multirow[t]{2}{*}{ PFGE type ${ }^{b}$} & \multicolumn{12}{|c|}{ MIC (ug/ml) of:c } \\
\hline & & & PEN & AUG & FRX & CRO & FTX & FEP & MEM & $\mathrm{CHL}$ & ERY & LEV & LID & SXT \\
\hline PI5Ia & $19 \mathrm{~F}$ & $\mathrm{~A} 2$ & 4 & 4 & $>4$ & 2 & 2 & 4 & I & 8 & $>2$ & 1 & 1 & $>4$ \\
\hline PI54a & $19 \mathrm{~F}$ & $\mathrm{~A} 2$ & 4 & 4 & $>4$ & 2 & 2 & 4 & I & 8 & $>2$ & 1 & 1 & $>4$ \\
\hline PI56a & $19 \mathrm{~F}$ & $\mathrm{~A} 2$ & 4 & 4 & $>4$ & 2 & 2 & 4 & 1 & 4 & $>2$ & 1 & 1 & $>4$ \\
\hline PI74 & $19 \mathrm{~F}$ & $\mathrm{Al}$ & 2 & $\leq 2$ & 4 & 1 & 1 & 0.5 & 0.5 & 8 & $>2$ & 1 & 2 & 4 \\
\hline PI76 & $19 \mathrm{~F}$ & $\mathrm{Al}$ & 2 & $\leq 2$ & 4 & 1 & 1 & 1 & 0.5 & 4 & $>2$ & 2 & 2 & 4 \\
\hline PI83 & $19 \mathrm{~F}$ & $\mathrm{Al}$ & 2 & $\leq 2$ & $>4$ & 1 & 1 & I & 0.5 & 8 & $>2$ & 1 & 2 & 4 \\
\hline PI86 & $19 \mathrm{~F}$ & $\mathrm{Al}$ & 2 & $\leq 2$ & 4 & 1 & I & 1 & 0.5 & 8 & $>2$ & 1 & 2 & 4 \\
\hline $\mathrm{PI} 92$ & $19 \mathrm{~F}$ & $\mathrm{Al}$ & 2 & $\leq 2$ & 4 & 1 & 1 & 1 & 0.5 & 4 & $>2$ & 2 & 2 & 4 \\
\hline PI98 & $19 \mathrm{~F}$ & $\mathrm{Al}$ & 2 & $\leq 2$ & $>4$ & 1 & 1 & 1 & 0.5 & 8 & $>2$ & 2 & 2 & 4 \\
\hline PI99 & $19 \mathrm{~F}$ & $\mathrm{Al}$ & 2 & $\leq 2$ & $>4$ & 1 & I & I & 0.5 & 8 & $>2$ & 1 & 2 & 4 \\
\hline P200 & $19 \mathrm{~F}$ & $\mathrm{Al}$ & 4 & $\leq 2$ & $>4$ & 1 & I & I & 0.5 & 4 & $>2$ & 1 & 2 & 4 \\
\hline P203 & $19 \mathrm{~F}$ & $\mathrm{Al}$ & 2 & $\leq 2$ & $>4$ & 1 & 1 & 2 & 0.5 & 8 & $>2$ & 2 & 2 & 4 \\
\hline P204 & $19 \mathrm{~F}$ & $\mathrm{Al}$ & 4 & $\leq 2$ & $>4$ & 1 & 1 & 1 & 0.5 & 4 & $>2$ & 1 & 2 & 4 \\
\hline PI79 & $19 \mathrm{~F}$ & & 4 & $\leq 2$ & $>4$ & 1 & I & 1 & 0.5 & 4 & $>2$ & 1 & 2 & 4 \\
\hline PI90 & $19 \mathrm{~F}$ & & 4 & $\leq 2$ & $>4$ & 2 & 2 & 2 & 0.5 & 4 & $>2$ & 1 & 1 & $>4$ \\
\hline PI77 & $6 \mathrm{~B}$ & $\mathrm{BI}$ & 4 & $\leq 2$ & $>4$ & I & I & I & 0.5 & 4 & $>2$ & 1 & 1 & $>4$ \\
\hline PI78 & $6 \mathrm{~B}$ & $\mathrm{BI}$ & 2 & $\leq 2$ & $>4$ & 1 & 1 & 1 & 0.5 & 4 & $>2$ & 1 & 2 & $>4$ \\
\hline PI80 & $6 \mathrm{~B}$ & $\mathrm{BI}$ & 4 & 4 & $>4$ & 1 & I & 1 & 0.5 & 4 & $>2$ & 1 & 2 & 4 \\
\hline PI8I & $6 \mathrm{~B}$ & $\mathrm{BI}$ & 4 & 4 & $>4$ & 1 & I & I & 0.5 & 4 & $>2$ & 1 & 1 & $>4$ \\
\hline PI85 & $6 \mathrm{~B}$ & $\mathrm{BI}$ & 4 & $\leq 2$ & $>4$ & 1 & 1 & I & 0.5 & 4 & $>2$ & 1 & 2 & $>4$ \\
\hline PI94 & $6 \mathrm{~B}$ & $\mathrm{BI}$ & 2 & $\leq 2$ & $>4$ & I & I & I & 0.5 & 4 & $>2$ & 1 & 2 & $>4$ \\
\hline PI95 & $6 \mathrm{~B}$ & $\mathrm{BI}$ & 2 & $\leq 2$ & $>4$ & 1 & 1 & 1 & 0.5 & 4 & $>2$ & 1 & 2 & $>4$ \\
\hline P20I & $6 \mathrm{~B}$ & $\mathrm{BI}$ & 4 & $\leq 2$ & $>4$ & 1 & 1 & 1 & 0.5 & 4 & $>2$ & 1 & 2 & $>4$ \\
\hline PI82 & $6 \mathrm{~B}$ & & 2 & $\leq 2$ & 4 & I & 0.5 & 1 & $\leq 0.25$ & 4 & $>2$ & I & 2 & $>4$ \\
\hline PI97 & $6 \mathrm{~B}$ & & $\leq 0.03$ & $\leq 2$ & $\leq 0.5$ & $\leq 0.06$ & $\leq 0.12$ & $\leq 0.12$ & $\leq 0.25$ & 4 & $\leq 0.25$ & $\leq 0.5$ & 1 & $\leq 0.5$ \\
\hline PI89 & $23 \mathrm{~F}$ & $\mathrm{Cl}$ & 2 & $\leq 2$ & $>4$ & I & 1 & I & $\leq 0.25$ & 8 & $>2$ & 1 & 2 & $\leq 0.5$ \\
\hline P205 & $23 \mathrm{~F}$ & $\mathrm{Cl}$ & 2 & $\leq 2$ & $>4$ & I & 1 & 1 & 0.5 & 8 & $>2$ & 1 & 2 & 4 \\
\hline PI75 & $23 \mathrm{~F}$ & & 4 & $\leq 2$ & $>4$ & 2 & 1 & 2 & 0.5 & 8 & $>2$ & 1 & 2 & 4 \\
\hline PI88 & $23 \mathrm{~F}$ & & 4 & $\leq 2$ & $>4$ & 2 & I & 2 & 0.5 & 8 & $>2$ & 1 & 2 & 4 \\
\hline PI96 & $23 \mathrm{~F}$ & & 2 & $\leq 2$ & $>4$ & 2 & I & 1 & 0.5 & 8 & $>2$ & 1 & 2 & $>4$ \\
\hline PI9I & $6 \mathrm{~A}$ & DI & $\leq 0.03$ & $\leq 2$ & $\leq 0.5$ & $\leq 0.06$ & $\leq 0.12$ & $\leq 0.12$ & $\leq 0.25$ & 4 & $>2$ & 1 & 1 & 4 \\
\hline P202 & $6 \mathrm{~A}$ & DI & 0.06 & $\leq 2$ & $\leq 0.5$ & $\leq 0.06$ & $\leq 0.12$ & $\leq 0.12$ & $\leq 0.25$ & 8 & $>2$ & 1 & 1 & 4 \\
\hline PI84 & $9 \mathrm{~V}$ & & 4 & 4 & $>4$ & 2 & 2 & 2 & 0.5 & 8 & $>2$ & 2 & 1 & $>4$ \\
\hline PI87 & 3 & & $\leq 0.03$ & $\leq 2$ & $\leq 0.5$ & $\leq 0.06$ & $\leq 0.12$ & $\leq 0.12$ & $\leq 0.25$ & 4 & $\leq 0.25$ & 2 & I & $\leq 0.5$ \\
\hline
\end{tabular}

a Isolates PI5I, PI54, and PI56 were from blood, nasopharynx, and CSF of the meningitis patient, respectively. All other isolates were from nasopharynx of children attending the same kindergarten as the patient.

b PFGE type, Pulse field gel electrophoresis pulsotype; see Figure I.

c AUG, amoxicillin/clavulanic acid; CHL, chloramphenicol; CRO, ceftriaxone; ERY, erythromycin; FEP, cefepime; FRX, cefuroxime; FTX, cefotaxime; LEV, levofloxacin; LID, Linezolid; MEM, meropenem; PEN, penicillin; SXT, trimethoprim/sulfamethoxazole. All isolates were resistant to tetracycline (MIC $>8 \mathrm{ug} / \mathrm{ml}$ ) except isolate PI87, which was susceptible (MIC $\leq 0.5 \mathrm{ug} / \mathrm{ml})$. All isolates were susceptible to vancomycin (MIC $\leq 0.5 \mathrm{ug} / \mathrm{ml})$.

\section{Pulsed field gel electrophoresis (PFGE)}

Molecular typing of the genomic DNA was performed by PFGE. Preparation of DNA plugs and subsequent digestion by SmaI was performed following previously published protocols [13]. After staining with ethidium bromide, restriction fragments were imaged with an IS1000 Digital Imaging System (Alpha Innotech Corporation, San Leandro, CA). PFGE patterns were analyzed using CHEF Mapper XA interactive software (version 1.2, Bio-Rad). International clones defined by the Pneumococcal Molecular Epidemiology Network (Spain ${ }^{23 \mathrm{~F}}-1$, Taiwan ${ }^{23 F_{-}}$15, Taiwan ${ }^{19 F}$-14, Spain ${ }^{6 B}-2$ ) were used for comparison [14]. Cluster analysis was performed and dendrograms were prepared by the unweighted pair group method with arithmetic averages with the Jaccard coefficient. PFGE pulsotypes were assigned to clusters of isolates based on the published criteria [15].

\section{Results}

S. pneumoniae was isolated from the nasopharynx of 32 $(41.0 \%)$ of the 78 children who attended the same kindergarten, including the index case (Table 1). The age of the children in the current study ranged from 4 to 6.5 years old. None of the children in the kindergarten including 


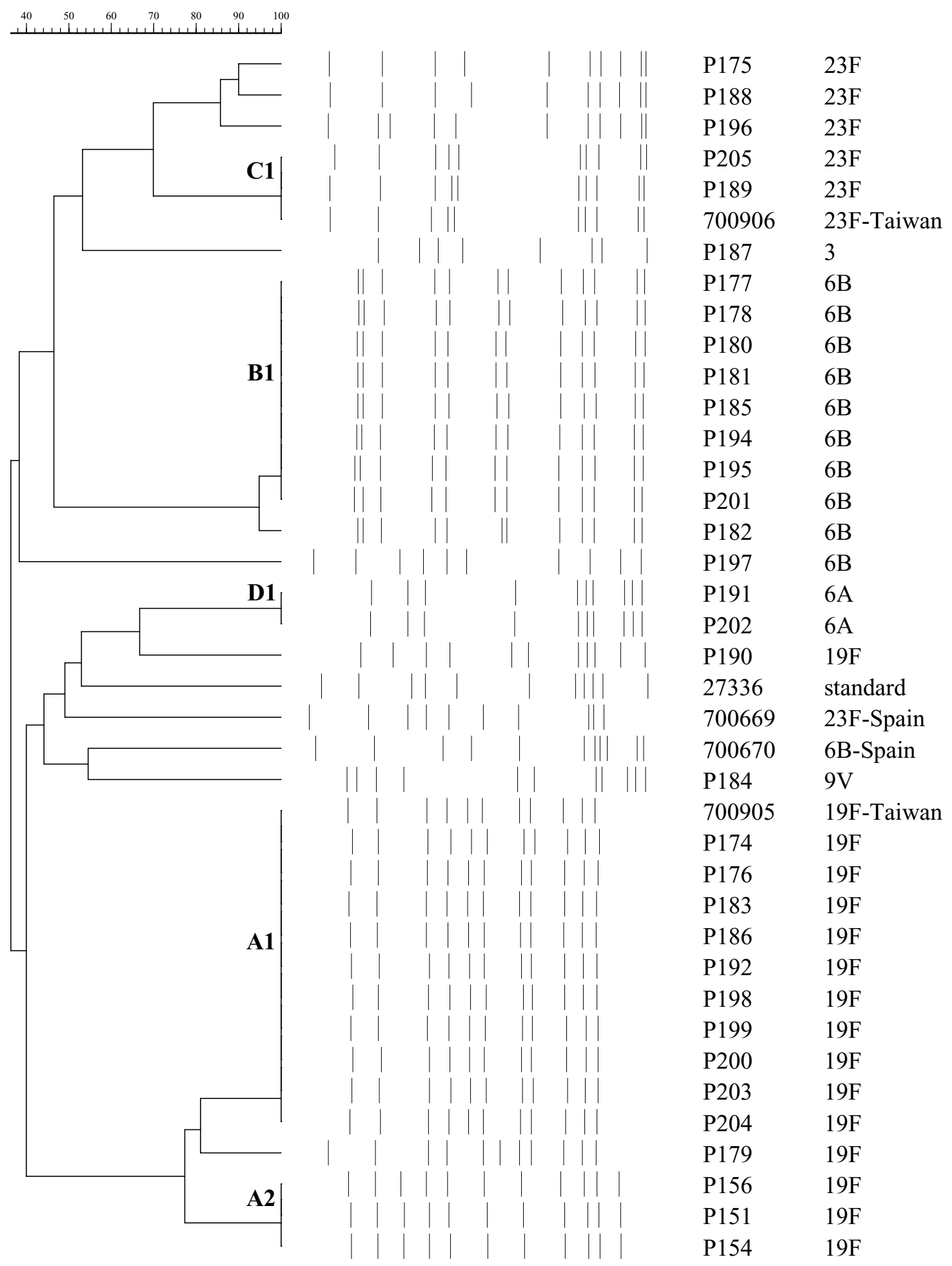

Figure I

Dendrogram of 34 S. pneumoniae pediatric isolates (isolates starting with P) based on PFGE results. Reference strains: 27336, R6; ATCC 700669, Spain²3F-I; ATCC 700670 Spain 6B-2; ATCC 700905 Taiwan 19F- I4; ATCC 700906 Taiwan23F-I5. 


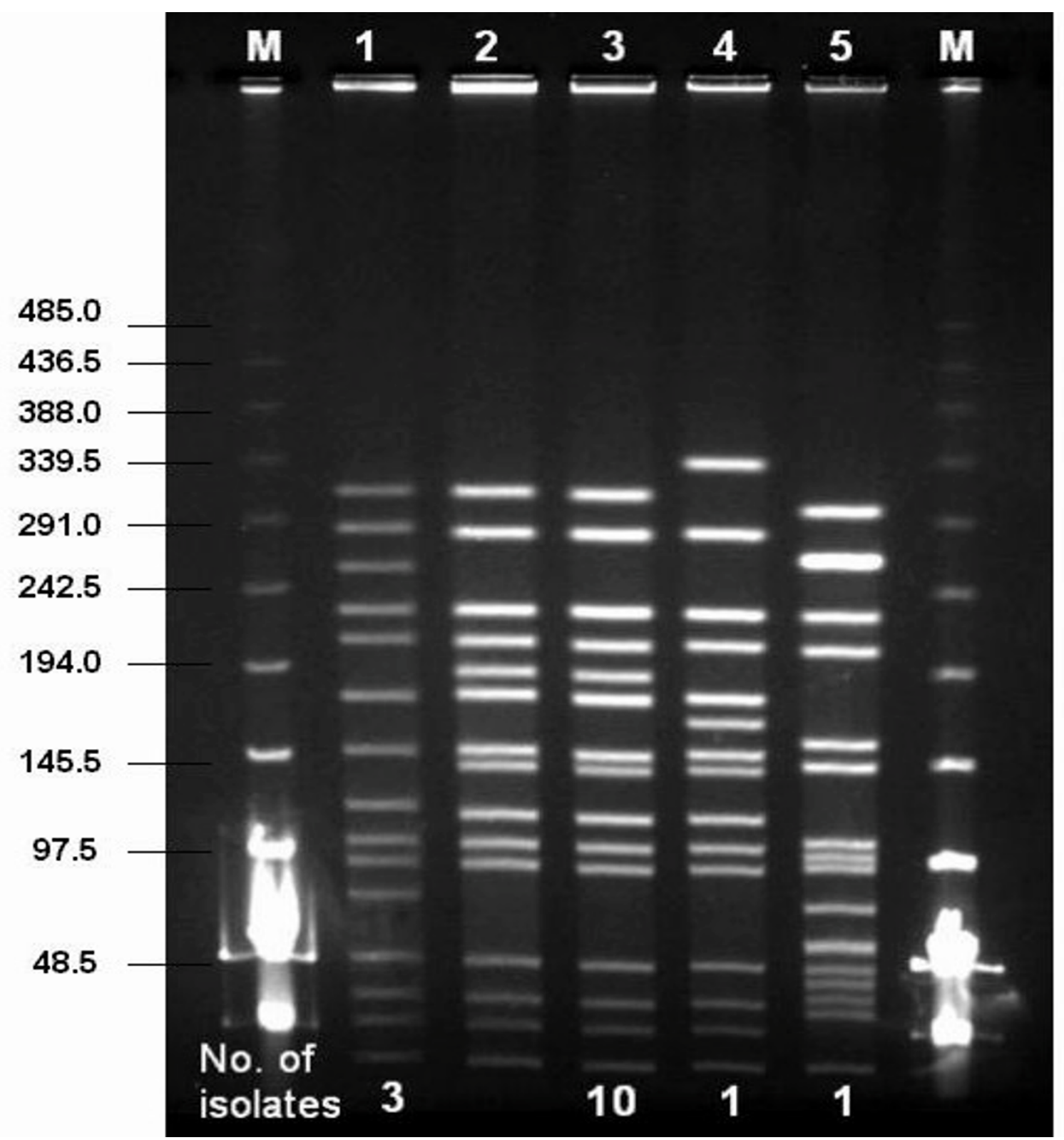

\section{Figure 2}

PFGE fingerprint patterns of Smal restriction digest of serotype I9F S. pneumoniae isolates. M, lambda ladder molecular size markers (shown in kbp); lane I, meningitis patient isolates; lane 2, ATCC700905 (Taiwan 19F- 14); lanes 3-5, other serotype $19 \mathrm{~F}$ nasopharyngeal isolates from children attending the same kindergarten as the patient. Numbers at the bottom of the gel indicate the number of isolates with the same pattern.

the index case had received conjugate pneumococcal vaccine. No $S$. pneumoniae was found in the nasopharynx of the parents and the younger sibling of the index case. A total of 34 isolates were available for further analysis including the CSF, blood and nasopharyngeal isolates from the index case and 31 isolates from the nasopharynx of the other children attending the kindergarten. The most common serotype isolated from the nasopharynx was $19 \mathrm{~F}$ 
$(13 / 32,40.6 \%)$. This was followed by serotypes 6B (10/ $32,31.3 \%$, ) and $23 \mathrm{~F}(5 / 32,15.6 \%)$. There were two isolates of serotype $6 \mathrm{~A}$ and one isolate each of serotypes $9 \mathrm{~V}$ and 3. The isolates of $S$. pneumoniae recovered from CSF, blood and nasopharynx of the index case were identical by PFGE (Figure 1, A2 pulsotype). Ten of the $1219 \mathrm{~F}$ isolates from the other children were identical to the Taiwan ${ }^{19 F}-14$ clone (Figure 1 A1 pulsotype, Figure 2 lanes 2 and 3). The isolates from the index case differed from the Taiwan ${ }^{19 \mathrm{~F}}-14$ clone by 4 bands, indicating it was a variant of the Taiwan ${ }^{19 F}$ - 14 clone (Figure $1 \mathrm{~A} 2$ and A1 pulsotypes, Figure 2 lanes 1 and 3).

All serotype $19 \mathrm{~F}$ isolates (15 isolates from 13 children) were high-level penicillin (MIC $\geq 2 \mathrm{ug} / \mathrm{ml}$ ) and multi-drug resistant. The three isolates from the case exhibited similar antibiogram as the other 12 serotype 19F nasopharyngeal isolates from his kindergarten contacts (Table 1). Although the 19F S. pneumoniae isolates exhibited similar antibiograms, the isolates from the patient were more resistant with higher amoxicillin/clavulanic acid, cefotaxime and cefepime MIC. In addition, based on meningitis interpretive criteria, isolates obtained from the index case were resistant to cefotaxime (MIC $2 \mathrm{ug} / \mathrm{ml}$ ), cefepime (MIC $4 \mathrm{ug} / \mathrm{ml}$ ), and ceftriaxone $(2 \mathrm{ug} / \mathrm{ml})$. The serotypes isolated from the other 19 children also exhibited highlevel penicillin resistance except for serotypes $6 \mathrm{~A}$ and a single strain of $6 \mathrm{~B}$, and 3 . The overall rate of highly penicillin resistant $S$. pneumoniae (MIC $2-4 \mu \mathrm{g} / \mathrm{ml}$ ) isolated from the nasopharynx of these 32 children was $87.5 \%$ (28/32). In addition, $13(40.6 \%)$ of these 32 isolates had a penicillin MIC of $\geq 4 \mathrm{ug} / \mathrm{ml}$. The rate of resistance to erythromycin, cefuroxime, trimethoprim/sulfamethoxazole and tetracycline were also high; at $93.8 \%(30 / 32)$, $87.5 \%(28 / 32), 90.6 \%(29 / 32)$ and $96.9 \%$ (31/32), respectively. Multi-drug resistant-isolates (isolates resistant to 3 different classes of antimicrobials) accounted for $87.5 \%(28 / 32)$ of all isolates. Most isolates remained susceptible to amoxicillin/clavulanic acid $(81.25 \%, 26 / 32)$ and cefotaxime $(84.4 \%, 27 / 32)$ despite the high prevalence of penicillin resistance. All isolates demonstrated universal susceptibility to all fluoroquinolones including gatifloxacin, gemifloxacin and moxifloxacin (data not shown) in addition to levofloxacin. All isolates were also uniformly susceptible to linezolid and vancomycin (Table $1)$.

\section{Discussion}

Nasopharyngeal carriage of $S$. pneumoniae in day-care center attendees has been well documented $[9,10,16,17]$. Studies have found the carriage rates to range from $44 \%-$ $65 \%$ at day-care centers, with one study reporting $53 \%$ of isolates highly resistant to penicillin, and another study reporting $13-19 \%$ of multi-drug resistance in serotype 14 isolates $[16,17]$. Taiwan has an extremely high carriage rate of penicillin-resistant $S$. pneumoniae among children attending day care centers and kindergartens [8]. The current report demonstrates an even higher nasopharyngeal carrier rate of penicillin resistant strains of $87.5 \%$ compared to $71.5 \%$ previously reported by our group [8]. In addition, $40.6 \%$ of the isolates in the present study had a penicillin MIC of $\geq 4 \mathrm{ug} / \mathrm{ml}$, the highest percent of isolates with such high MICs reported in the literature $[1-4,6]$. The absence of resistance to fluoroquinolones is probably related to their uncommon use by pediatricians.

It is unclear why $41.0 \%$ of the children in the Kindergarten carried a variety of strains of $S$. pneumoniae yet only one child developed bacterial meningitis with serotype 19F. The child did not have history of recurrent infection and his immunoglobulin profiles were normal. It is unlikely that he had a congenital or acquired immunodeficiency or asplenia that predisposed him to invasive pneumococcal infection. Further studies are needed to determine if the invading strain is more virulent than the others. We have no ready explanation why the S. pneumoniae serotype $19 \mathrm{~F}$ isolated from the index case exhibited a different albeit possibly related PFGE pattern from those isolated from his kindergarten contacts. The nasopharyngeal swab was collected at the same time as the CSF and blood cultures. We do not know how long the patient was colonized before the onset of his disease. However, it is well recognized that nasopharyngeal colonization precedes pneumococcal infection and studies have shown that $S$. pneumoniae strains recovered from the CSF of the meningitis patients to be the same as the strains carried in the nasopharynx of patients $[18,19]$.

The Taiwan ${ }^{19 F}$ clone is the most common serotype that causes pneumococcal diseases in Asian countries [20]. A recent study of $S$. pneumoniae isolates from patients with meningitis in Japan found high-level penicillin resistance to be associated with the presence of multiple (three) abnormal penicillin binding protein ( $p b p)$ genes. Serotype $19 \mathrm{~F}$ was among those showing the greatest high-level penicillin resistance [6]. Another report from Japan found that the most prevalent serotype in a major Japanese medical center to be 19F, the majority of which were Taiwan ${ }^{19 F}-14$ clone and its variants [21]. High-level antibiotic resistant strains of the Taiwan ${ }^{19 \mathrm{~F}}$ clone and its variants are also relatively common in invasive and noninvasive pneumococcal infections in New Zealand $[13,22]$.

The other serotypes isolated from children in the current study were similar to those encountered in our previous surveillance studies of day care centers and kindergartens in Kaohsiung, in which serotype $23 \mathrm{~F}$ was the most common, followed by 19F, 6B, 6A, and 14 [23]. We were surprised by the absence of serotype 14, a serotype 
commonly found in nasopharyngeal and invasive isolates in children $\leq 5$ years old, especially those $\leq 2$ years old $[3,4,24]$. The differences between the current and previous studies in the distribution of serotypes may be accounted for by differences in the ages of the children. The children in the current study were older ( $4-6.5$ years) compared to 2 months to 7 years in the prior study.

\section{Conclusion}

S. pneumoniae and Neisseria meningitidis became the leading causes of meningitis in the United States and Netherlands after the widespread use of $H$. influenzae type b vaccine [5]. With the introduction of conjugate pneumococcal vaccine, there is now considerable evidence showing substantial decreases in invasive pneumococcal diseases and concomitant penicillin resistance in vaccine and vaccine-related serotypes in children who were vaccinated $[25,26]$. Although we did not find S. pneumoniae carriage in the parents and the young sibling of the index case, spread of $S$. pneumoniae and antibiotic-resistant serotypes from day-care center attendees to their siblings has been reported $[17,27]$. In addition, prior antibiotic use has been shown to contribute to increased $S$. pneumoniae colonization and diseases [16,17,28]. In February 2001 the Bureau of National Health Insurance in Taiwan implemented a new rule restricting antimicrobial prescription for acute upper respiratory infections in ambulatory patients. This has significantly decreased antimicrobial consumption in this country. Nevertheless, there are still an excessive number of ambulatory patient visits for respiratory infections resulting in antimicrobials being prescribed [29]. It is hoped that a combination of restraint in antibiotic use and implementation of childhood immunization with conjugate pneumococcal vaccine can reduce the burden of pneumococcal illness and multidrug resistant strains in Taiwan and other countries.

\section{Competing interests}

The author(s) declare that they have no competing interests.

\section{Authors' contributions}

TLL supervised the molecular study and antimicrobial susceptibility testing, carried out the analysis, and prepared the final manuscript. WYL assisted in specimen and data collection of the children attending the kindergarten, and identification and shipment of specimen. MFC, IFH, YCL, and $\mathrm{KSH}$ assisted in taking care of the patients and specimen collection. IWH carried out the molecular and antimicrobial susceptibility testing. CCC conceived and coordinated the study, carried out the specimen collection and analysis, and prepared the draft manuscript.

\section{Acknowledgements}

We thank Jui-Fen Lai for her assistance in serotyping. We also wish to thank Dr. Calvin M. Kunin for his helpful review of the manuscript. This work was supported in part by an intramural grant from the National Health Research Institutes (CL-093-PP-0I) and a grant from the Veterans General Hospital - Kaohsiung, Taiwan (VGHKS92-8I).

\section{References}

I. de Andrade AL, Pimenta FC, Laval CA, de Andrade JG, Guerra ML, Brandileone MC: Invasive pneumococcal infection in a healthy infant caused by two different serotypes. J Clin Microbiol 2004, 42:2345-6.

2. Di Fabio JL, Castaneda E., Agudelo Cl, De La HF, Hortal M, Camou T, Echaniz-Aviles G, Noemi M, Barajas C, Heitmann I, Hormazabal JC, Brandileone MC, Dias V, Regueira M, Ruvinski R, Corso A, Lovgren $M$, Talbot JA, De Quadros C: Evolution of Streptococcus pneumoniae serotypes and penicillin susceptibility in Latin America, Sireva-Vigia Group, 1993 to 1999. PAHO Sireva-Vigia Study Group. Pan American Health Organization. Pediatr Infect Dis J 200I, 20:959-967.

3. Doit C, Loukil C, Geslin P, Bingen E: Phenotypic and genetic diversity of invasive pneumococcal isolates recovered from French children. J Clin Microbiol 2002, 40:2994-8.

4. Pantosti A, D'Ambrosio F, Tarasi A, Recchia S, Orefici G, Mastrantonio $P$ : Antibiotic susceptibility and serotype distribution of Streptococcus pneumoniae causing meningitis in Italy, 19971999. Clin Infect Dis 2000, 31 : 1373-9.

5. Swartz MN: Bacterial meningitis - a view of the past $\mathbf{9 0}$ years. N Engl J Med 2004, 35 I : I826-8.

6. Ubukata K, Chiba N, Hasegawa K, Kobayashi R, Iwata S, Sunakawa K: Antibiotic susceptibility in relation to penicillin-binding protein genes and serotype distribution of Streptococcus pneumoniae strains responsible for meningitis in Japan, 1999 to 2002. Antimicrob Agents Chemother 2004, 48: I488-94.

7. Barnes DM, Whittier S, Gilligan PH, Soares S, Tomasz A, Henderson FW: Transmission of multidrug-resistant serotype 23F Streptococcus pneumoniae in group day care: evidence suggesting capsular transformation of the resistant strain in vivo. J Infect Dis 1995, I 71:890-6.

8. Chiou CC, Liu YC, Huang TS, Hwang WK, Wang JH, Lin HH, Yen MY, Hsieh KS: Extremely high prevalence of nasopharyngeal carriage of penicillin-resistant Streptococcus pneumoniae among children in Kaohsiung, Taiwan. J Clin Microbiol 1998, 36: 1933-7.

9. Reichler MR, Allphin AA, Breiman RF, Schreiber JR, Arnold JE, McDougal LK, Facklam RR, Boxerbaum B, May D, Walton RO: The spread of multiply resistant Streptococcus pneumoniae at a day care center in Ohio. J Infect Dis 1992, I 66:1346-53.

10. Dagan R, O'Brien KL: Modeling the association between pneumococcal carriage and child-care center attendance. Clin Infect Dis 2005, 40: I 223-6.

II. Clinical and Laboratory Standards Institute (formerly NCCLS): Methods for Dilution Antimicrobial Susceptibility Tests for Bacteria That Grow Aerobically, Approved Standard - Sixth Edition. M7-A6. Clinical and Laboratory Standards Institute. Wayne, PA; 2003.

12. Clinical and Laboratory Standards Institute (formerly NCCLS): Performance standards for antimicrobial susceptibility testing, I4th informational supplement. MI00-S I 4. Clinical and Laboratory Standards Institute. Wayne, PA; 2004.

13. Bean DC, Ikram RB, Klena JD: Molecular characterization of penicillin non-susceptible Streptococcus pneumoniae in Christchurch, New Zealand. J Antimicrob Chemother 2004, 54:122-9.

14. McGee L, McDougal L, Zhou J, Spratt BG, Tenover FC, George R, Hakenbeck R, Hryniewicz W, Lefevre JC, Tomasz A, Klugman KP: Nomenclature of major antimicrobial-resistant clones of Streptococcus pneumoniae defined by the pneumococcal molecular epidemiology network. J Clin Microbiol 200I, 39:2565-7I.

15. Tenover FC, Arbeit RD, Goering RV, Mickelsen PA, Murray BE, Persing $\mathrm{DH}$, Swaminathan $\mathrm{B}$ : Interpreting chromosomal DNA restriction patterns produced by pulsed-field gel electrophoresis: criteria for bacterial strain typing. J Clin Microbiol 1995, 33:2233-9.

16. Boken DJ, Chartrand SA, Goering RV, Kruger R, Harrison CJ: Colonization with penicillin-resistant Streptococcus pneumoniae in a child-care center. Pediatr Infect Dis J 1995, I4:879-84.

17. Craig AS, Erwin PC, Schaffner W, Elliott JA, Moore WL, Ussery XT, Patterson L, Dake AD, Hannah SG, Butler JC: Carriage of multid- 
rug-resistant Streptococcus pneumoniae and impact of chemoprophylaxis during an outbreak of meningitis at a day care center. Clin Infect Dis 1999, 29:1257-64.

18. Bogaert D, De Groot R, Hermans PW: Streptococcus pneumoniae colonisation: the key to pneumococcal disease. Lancet Infect Dis 2004, 4: 144-54.

19. de Andrade AL, Pimenta FC, Brandileone MC, Laval CA, Guerra ML de Andrade JG, Di Fabio JL: Genetic relationship between Streptococcus pneumoniae isolates from nasopharyngeal and cerebrospinal fluid of two infants with Pneumococcal Meningitis. J Clin Microbiol 2003, 4 I:3970-2.

20. Song JH, Jung SI, Ko KS, Kim NY, Son JS, Chang HH, Ki HK, Oh WS, Suh JY, Peck KR, Lee NY, Yang Y, Lu Q, Chongthaleong A, Chiu CH, Lalitha MK, Perera J, Yee TT, Kumarasinghe G, Jamal F, Kamarulzaman A, Parasakthi N, Van PH, Carlos C, So T, Ng TK, Shibl A: High prevalence of antimicrobial resistance among clinical Streptococcus pneumoniae isolates in Asia (an ANSORP study). Antimicrob Agents Chemother 2004, 48:2I 0I-7.

21. Kasahara K, Maeda K, Mikasa K, Uno K, Takahashi K, Konishi M, Yoshimoto E, Murakawa K, Kita E, Kimura H: Clonal dissemination of macrolide-resistant and penicillin-susceptible serotype 3 and penicillin-resistant Taiwan I9F-14 and 23F-15 Streptococcus pneumoniae isolates in Japan: a Pilot Surveillance Study. J Clin Microbiol 2005, 43:1640-1645.

22. Bean DC, Klena JD: Characterization of major clones of antibiotic-resistant Streptococcus pneumoniae in New Zealand by multilocus sequence typing. I Antimicrob Chemother 2005, 55:375-8.

23. Chiou CC, McEllistrem MC: Novel penicillin-, cephalosporin-, and macrolide-resistant clones of Streptococcus pneumoniae serotypes 23F and I9F in Taiwan which differ from international epidemic clones. / Clin Microbiol 200I, 39: I I44-7.

24. Hausdorff WP, Feikin DR, Klugman KP: Epidemiological differences among pneumococcal serotypes. Lancet Infect Dis 2005, 5:83-93.

25. Bogaert D, Hermans PW, Adrian PV, Rumke HC, de Groot R: Pneumococcal vaccines: an update on current strategies. Vaccine 2004, 22:2209-20.

26. Kaplan SL, Mason EO Jr, Wald ER, Schutze GE, Bradley JS, Tan TQ, Hoffman JA, Givner LB, Yogev R, Barson WJ: Decrease of invasive pneumococcal infections in children among 8 children's hospitals in the United States after the introduction of the 7 . valent pneumococcal conjugate vaccine. Pediatrics 2004, I I 3:443-9.

27. Givon-Lavi N, Fraser D, Porat N, Dagan R: Spread of Streptococcus pneumoniae and antibiotic-resistant $S$. pneumoniae from day-care center attendees to their younger siblings. J Infect Dis 2002, 186:|608-|4.

28. Radetsky MS, Istre GR, Johansen TL, Parmelee SW, Lauer BA, Wiesenthal AM, Glode MP: Multiply resistant pneumococcus causing meningitis: its epidemiology within a day-care centre. Lancet I98I, 2:77|-3.

29. Ho M, Hsiung CA, Yu HT, Chi CL, Yin HC, Chang HJ: Antimicrobial usage in ambulatory patients with respiratory infections in Taiwan, 200I. J Formos Med Assoc 2004, 103:96-103.

\section{Pre-publication history}

The pre-publication history for this paper can be accessed here:

http://www.biomedcentral.com/1471-2334/5/96/prepub 